
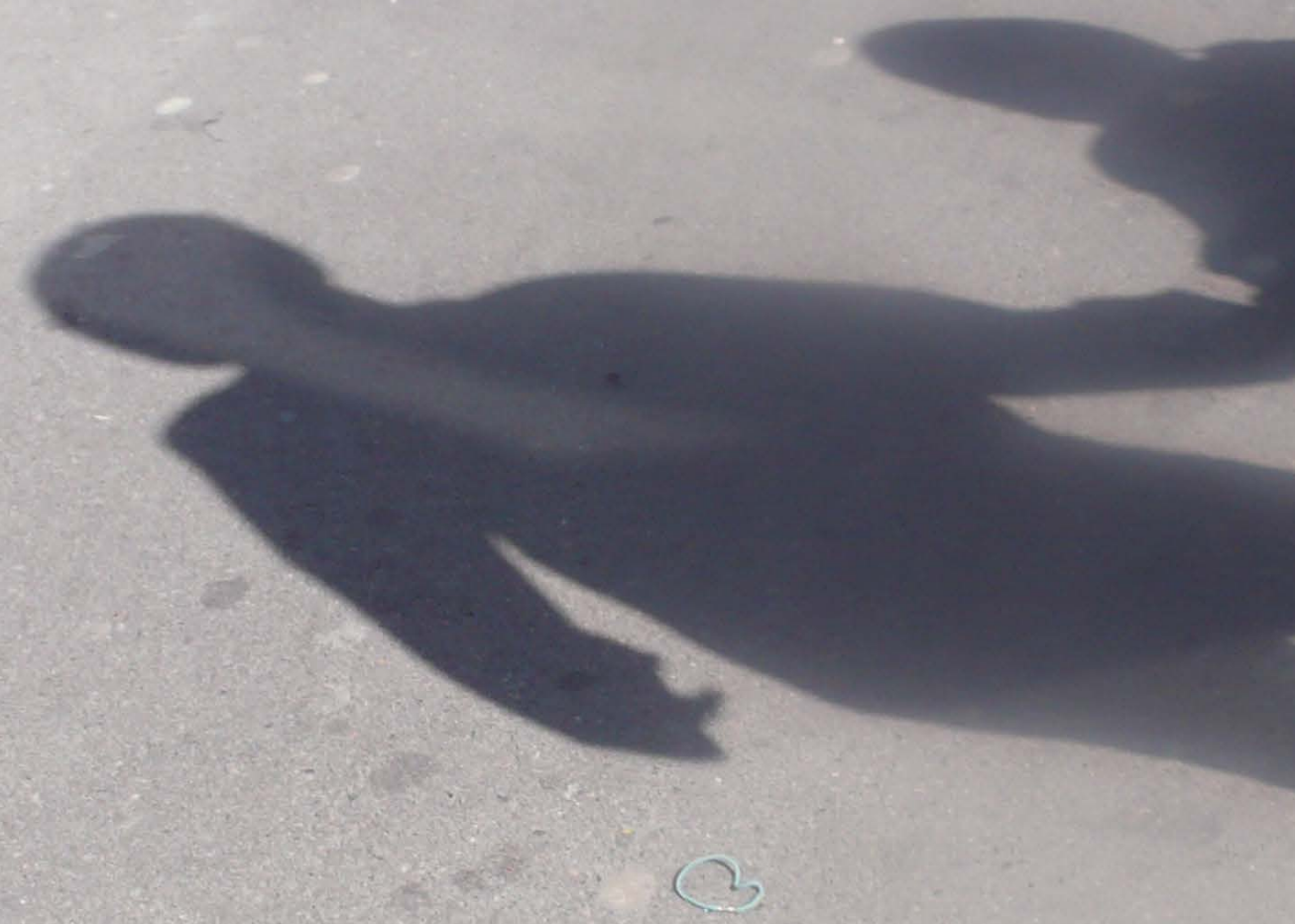


\section{POR DENTRO E POR FORA}

Botika

A sombra que persegue os teus passos

É tua companheira, extensão

Não tenha medo não da escuridão

Que ela te envolve e te pertence

E juntas vocês andam agarradas

Conversam sem palavras sobre tudo e nada

Desmancham e refazem toda invenção

Parece não haver explicação

Agora olha pra cima

É filha de sol que te ilumina

É filha desse grande lampião

É filha da luz fria e do luar

Parece até que é tua projeção

Mas não é (?)

É filha de um fósforo riscado

É filha de um flash fotográfico

É filha da penumbra e do clarão

Por dentro você tem o mesmo breu

Por dentro e por fora o mesmo breu 


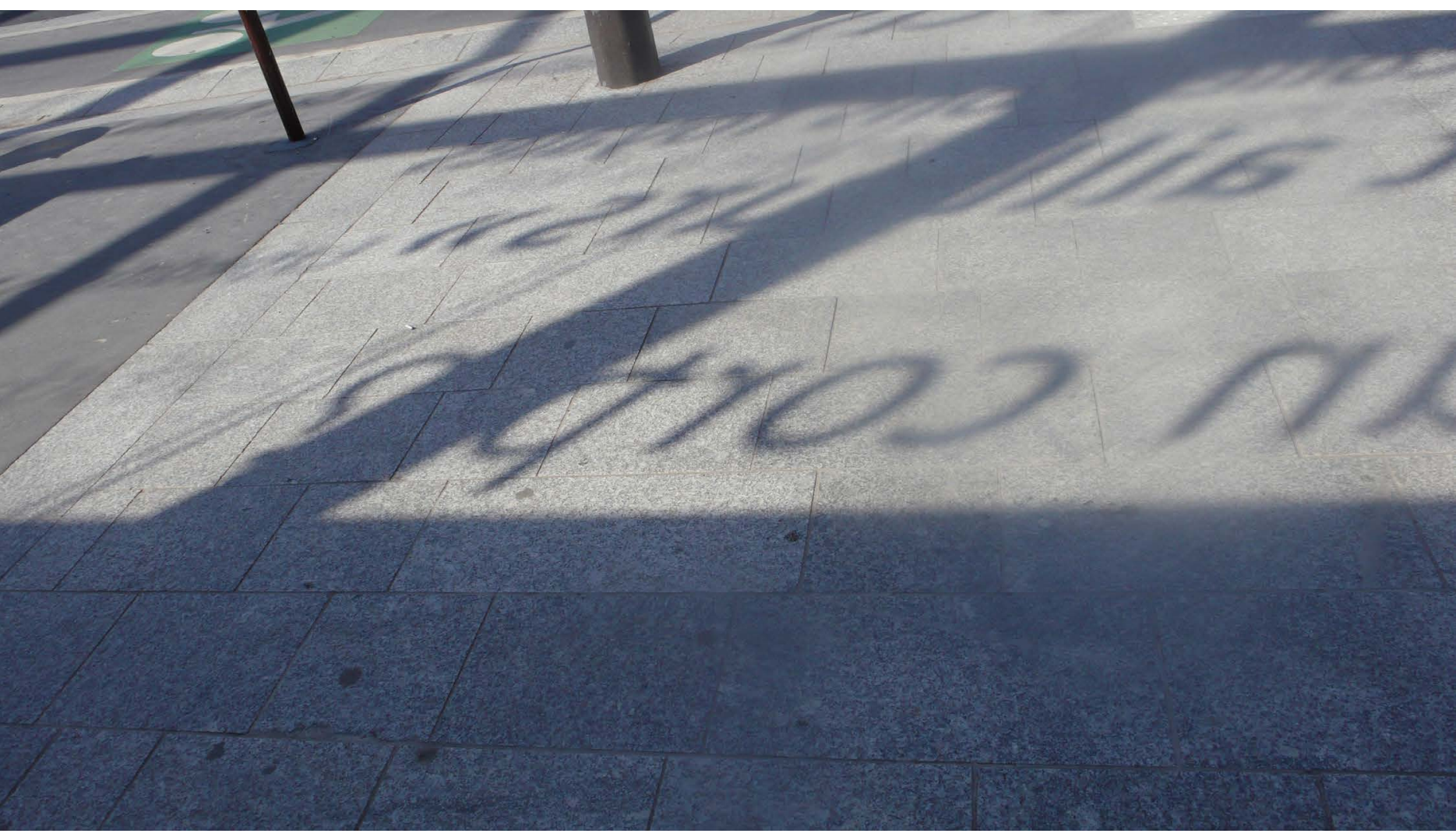




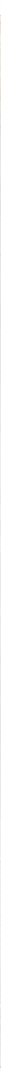




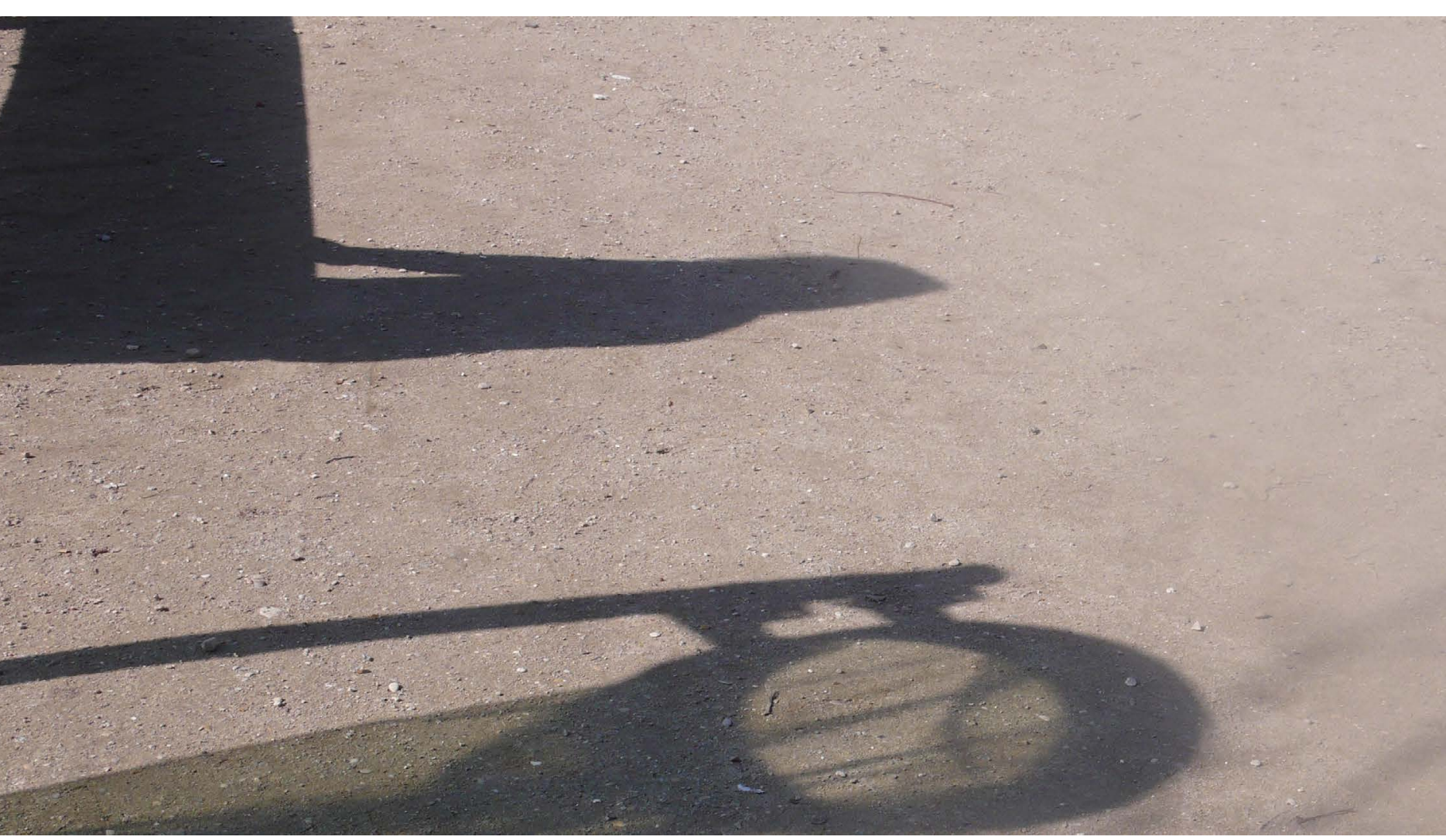




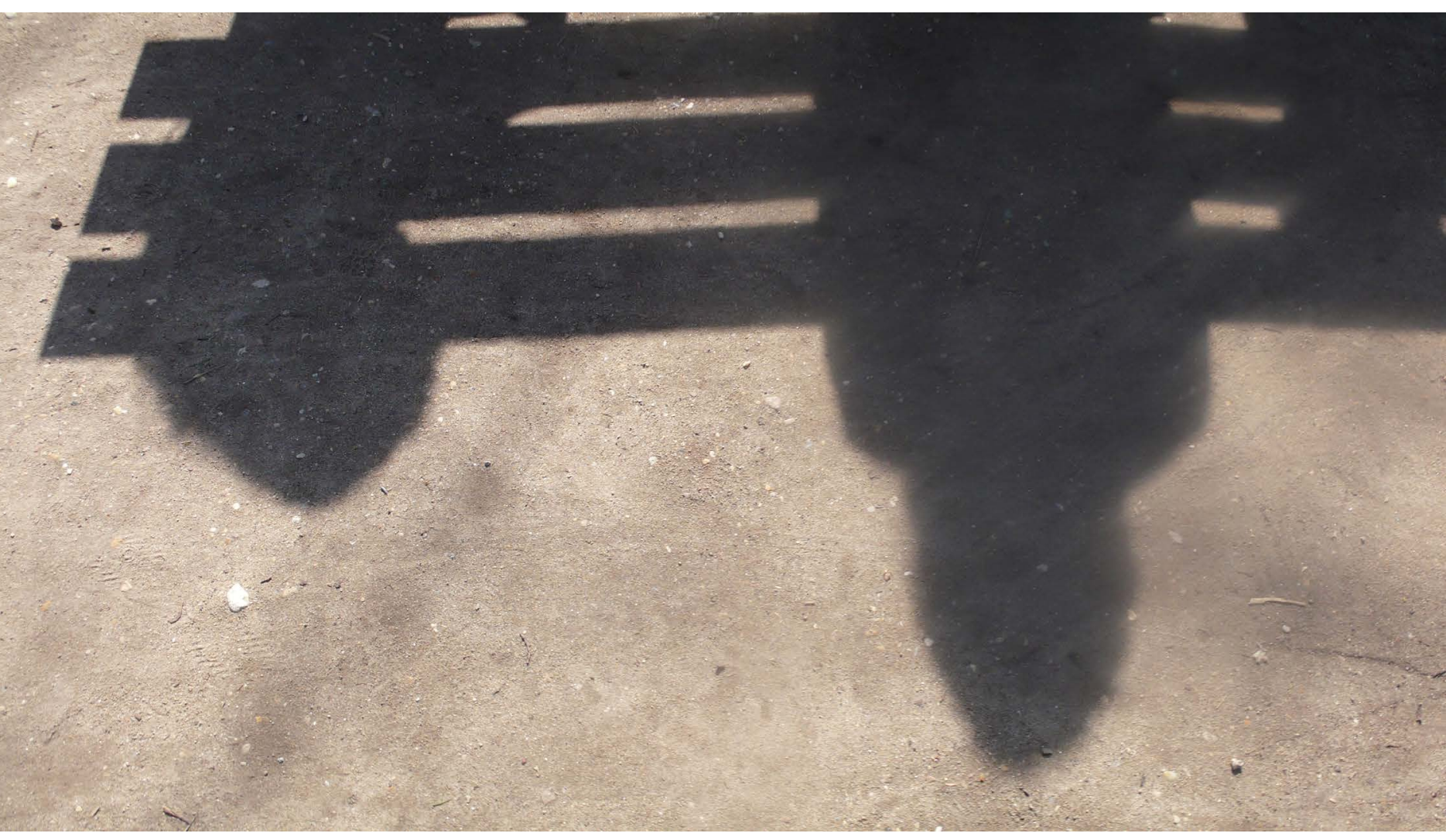




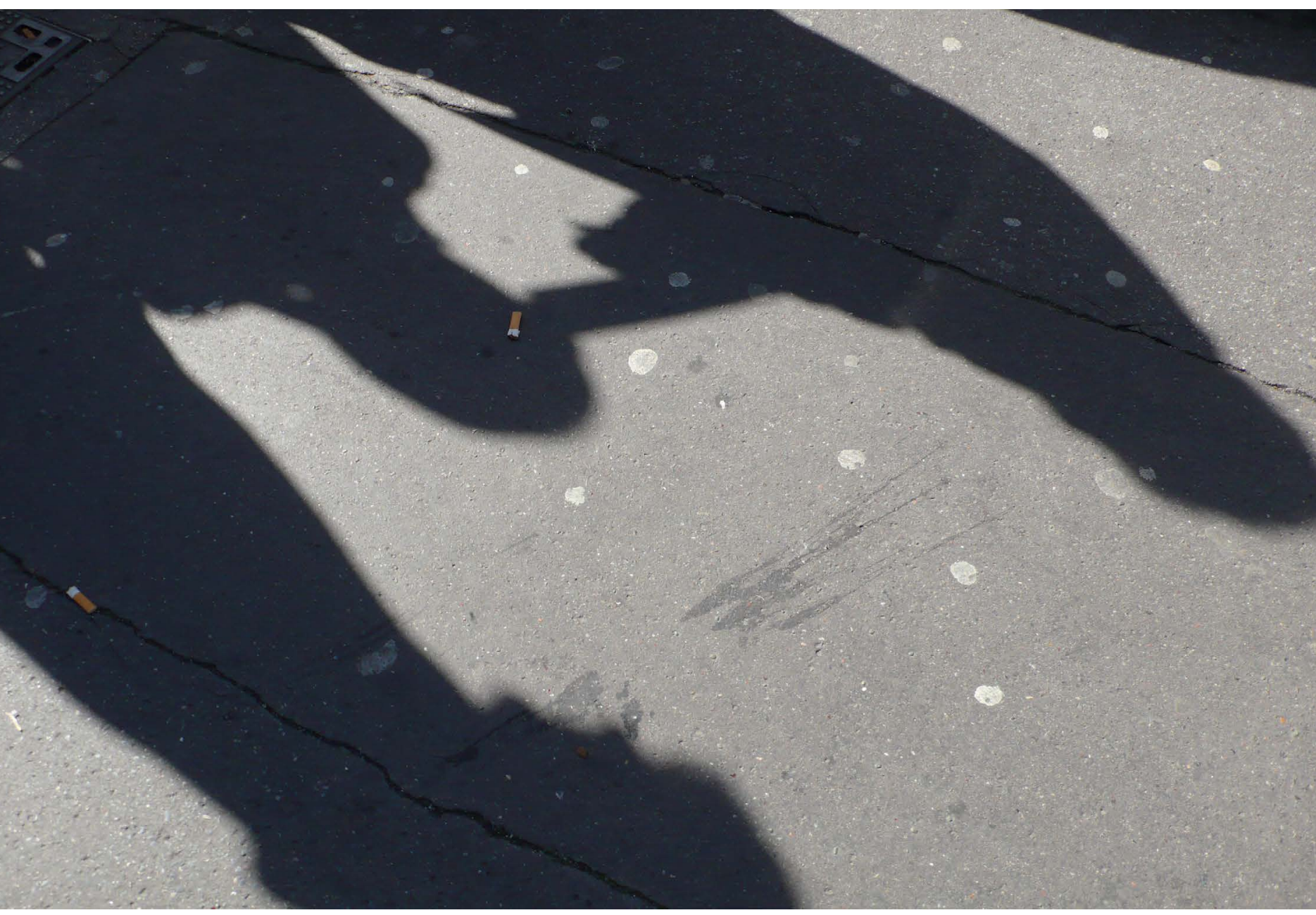




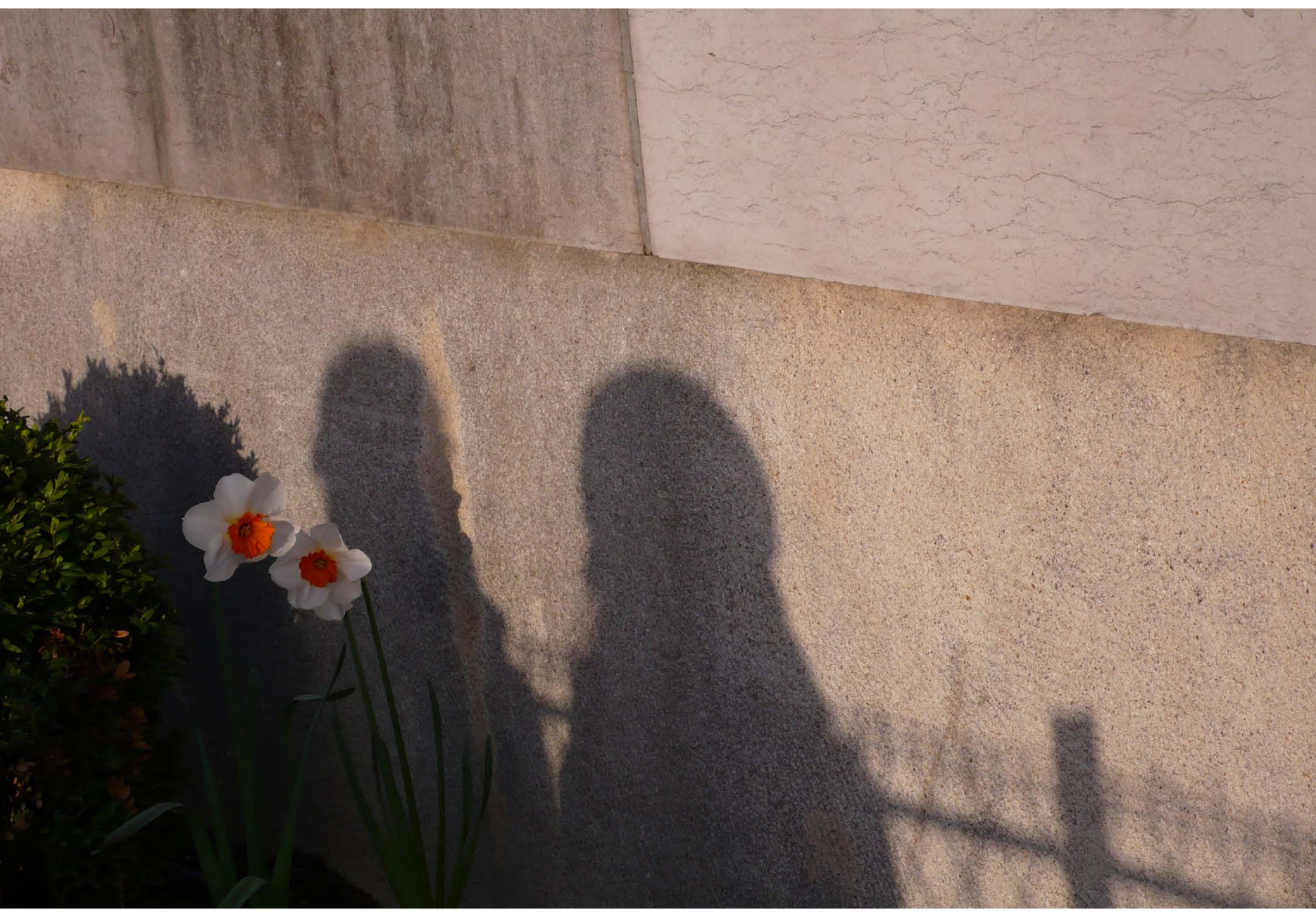

Dossiê organizado por Ronald Duarte com fotos de Glória Ferreira e poema/música de Botika. 